\title{
A construção de mundos na ficção televisiva e a questão do realismo: o caso de The Wire ${ }^{1}$
}

\section{Worldbuilding in TV fiction and the issue of realism: the case of The Wire}

João Eduardo Silva de Araújo² e Maria Carmen Jacob de Souza ${ }^{3}$ 


\section{Resumo}

Este artigo busca contribuir com as discussões sobre as especificidades das séries ficcionais realistas, sobretudo no que concerne à capacidade que estas obras com frequência têm de gerar um efeito de crença que parece apagar a distinção entre o mundo da ficção e o mundo vivido. Abraçando a questão das diretrizes autorais que orientam uma obra como uma via importante para compreender as dimensões poéticas internas que promovem esses efeitos, este artigo explora como o impulso jornalístico que moveu o autor-criador de The Wire, David Simon, incitou a construção de um universo narrativo singular no seriado e a criação de uma forte ilusão de realidade por ele.

Palavras-chave

Mundos ficcionais, ficção televisiva, realismo, autoria, The Wire.

\section{Abstract}

This paper aims to contribute to the debate on fictional television shows in which a realistic approach is patent, focusing on the ability such works oftentimes display to generate a level of belief that seems to erase the distinction between their fictional worlds and our own. Embracing the issue of authorial guidelines as important factors in understanding the poetic aspects of a work, this paper explores how the journalistic impulse which moved The Wire's creator, David Simon, drove the creation of a unique world in the series the casting of a strong reality effect upon said world.

\section{Keywords}

Fictional worlds, television fiction, realism, authorship, The Wire. 
Uma passagem rápida por algumas das obras mais importantes escritas pelos teóricos que ajudaram a estabelecer na academia o tema da construção de mundos narrativos permite-nos entender que qualquer obra - das mais realistas às mais fantásticas - cria seus próprios universos de referência 4 . Quer nos encontremos diante da Terra Média de Tolkien ou do Rio de Janeiro de uma telenovela de Manoel Carlos, para os estudiosos do tema dos mundos narrativos, sempre estamos lidando com mundos de ficção. Conforme argumentam, narrativas ficcionais operam justamente acrescentando atributos, indivíduos, eventos e lugares a cidades que supostamente são as do mundo em que vive o apreciador, tornando as versões que criam destas cidades, por um lado, maiores do que as que podemos de fato visitar.

Por outro lado, estas geografias imaginárias não englobam as suas contrapartes no nosso mundo inteiras, só fragmentos, sendo a um só tempo também menores que elas, criando nesse jogo de cortes e acréscimos ambientes únicos, que engajam por sua própria ficcionalidade (ECO, 2006). Afinal, como pontuam Goodman (1995) e Herman (2009), insumos do nosso mundo, ou até de outros mundos ficcionais, são inevitavelmente decompostos, recompostos, suprimidos, completados, deformados ou enfatizados na criação de qualquer produto ficcional.

Ainda assim, é inegável que as narrativas ficcionais tidas como realistas com frequência encantam pela capacidade de produzir sentidos que imprimem a crença de que representam diretamente o mundo em que vivemos. Mais ainda, nos ajudam a compreendê-lo com tão intensa sensação de veridicidade que há até mesmo quem reivindique para a ficção realista um teor documental. Neste artigo, o leitor é convocado a compreender os modos como as séries ficcionais realistas para televisão e internet compõem esse efeito de crença que parece apagar a distinção entre o mundo da ficção e o mundo vivido, ao mesmo tempo em que cria os seus próprios mundos narrativos. Para tanto, dimensões formais e contextuais são contempladas aqui com o intuito de explorar como as texturas expressivas das 
séries realistas se organizam de modo a provocar esses efeitos de real em quem as consome, mobilizando suas emoções e sentidos. Essa dupla atenção - formal e contextual - encontra sua ancoragem em uma abordagem poética de tradição aristotélica, que salienta o exame dos processos pelos quais as texturas formais de um meio são manipuladas na configuração de obras que ganham força apenas quando operam efeitos em quem as consome (VALÉRY, [1938] 1999). Tal perspectiva incita, assim, justamente o exame da força criadora da poiese que marca tanto as atividades das equipes criativas quanto os meios expressivos que conformam o resultado do fazer artístico (BORDWELL, 1989; GOMES, 1996).

Ou seja, para nós, na esteira de uma abordagem poética, a compreensão de como uma série de proposta realista convoca ilusões de realidade em seus apreciadores ao mesmo tempo em que cria um mundo único só tem a avançar quando analistas se propõem a empreender exames formais que deem ênfase também às diretrizes autorais de uma equipe criativa. Vale lembrar, contudo, que considerar as escolhas gestadas pelas diretrizes autorais não significa assumir que a relação entre intenções dos autores e resultados conseguidos na ficção seriada é direta. Ao contrário, dar peso analítico às escolhas dos criadores na análise das texturas formais de uma obra implica, sobretudo, na engenharia reversa (BORDWELL, 2008) que prima pelo cuidado de identificar como, e em que medida, uma equipe produtiva maneja os recursos expressivos de um meio para tentar concretizar certas visões criativas, com todos os atalhos e desvios que isto implica. Cabe pontuar ainda que essa abordagem das dimensões formais e contextuais mediada pelas diretrizes criativas é amparada por estudiosos que lidam com o desafio de associar o cotejamento interno de uma obra com as condições de produção, distribuição e consumo que atravessam a superfície formal que as constitui (BAXANDALL, 2005; BORDWELL, 2008; BOURDIEU, 2005; MITTELL, 2015).

A perspectiva adotada aqui entende, assim, que as escolhas estilísticas observadas na ficção seriada audiovisual se relacionam com as diretrizes autorais que as orientaram. Dado que os modos como uma determinada obra configura seus efeitos de real deve muito às próprias noções de realidade e realismo caras aos 
autores daquela obra (THOMPSON, 1988), a nosso ver essa é uma premissa importante para compreender porque uma determinada série realista abraça certos procedimentos formais e não outros para produzir efeitos de real junto aos apreciadores. Concebe-se aqui, ainda, que estas diretrizes criativas remetem a agentes específicos responsáveis por essas escolhas que atuaram em circunstâncias contextuais particulares, alguns dos quais ganham mais peso relativo nos processos produtivos e são reconhecidos como autores das obras mesmo em sistemas coletivos de produção, como ocorre na ficção televisiva - meio no qual a atribuição da autoria sempre foi muito variável conforme realidades nacionais, mas em diversos contextos de produção tende a ressaltar o papel dos roteiristas (ARAÚJO, 2019). Especificamente na conjuntura estadunidense, o forte modelo gerencial faz com que a atribuição autoral recaia sobre um produtor executivo que às vezes assume também o papel do diretor, mas quase sempre lidera a equipe de roteiro (TOUS-ROVIROSA, 2009).

Por certo, essa atribuição de autoria em mídias que implicam forte trabalho coletivo é densamente ancorada em fatores sociais, mas argumentamos que ela não deixa de implicar que a visão criativa de certos agentes reconhecidos como autores acaba ganhando mais peso por conta disso, de modo que é uma boa chave analítica localizá-los e mapear a partir de suas trajetórias e discursos as diretrizes criativas que orientam a equipe na condução de uma obra. Por fim, certamente o interesse em observar como as diretrizes de uma equipe criativa impactam na construção de um mundo narrativo marcado por efeitos de realidade torna necessária a escolha de um caso singular para a análise. Nesse sentido, nenhum corpus parece-nos mais adequado para ilustrar os argumentos propostos neste artigo do que The Wire (HBO, 2002 a 2008), tido por boa parte da crítica como possivelmente o seriado mais realista de todos os tempos (cf. ARAúJO, 2019; MITTELL, 2015; WILLIAMS, 2014)5. equipes locais da cidade Baltimore, que recriava ficcionalmente e onde era filmada, além de abraçar atores desconhecidos ou não atores, gravações in loco e uma iluminação naturalista. Sua premissa é a de explorar um inquérito policial a cada uma de suas temporadas, abordando a relação da polícia com distintas instituições no processo. 
E aqui, cabe pontuar que inegavelmente a figura autoral mais importante da série é David Simon, criador, roteirista-titular e showrunner/produtor-executivo chefe da obra6 ${ }^{6}$. Formado em jornalismo pela Universidade de Maryland; antes de The Wire, Simon trabalhou no periódico The Baltimore Sun por mais de uma década, permanecendo empregado no jornal entre 1982 e 1995 - boa parte deste tempo como correspondente de polícia. Ali, ele logo se tornou contrário às mudanças introduzidas na estrutura dos impressos estadunidenses com as fusões corporativas dos anos 1990. Isso porque Simon enxergava na promoção de editores externos trazidos pelas empresas matrizes a cargos de chefia e no aumento considerável nas margens de lucro tidas como aceitáveis - e não na internet - a razão para o declínio do jornalismo tradicional (SIMON, 2004; SIMON et al., 2016). Por conta disso, perto do fim do seu período como repórter, o descontentamento dele com o trabalho foi piorando, o que o levou a pedir licença por um ano para produzir um livro-reportagem, sendo esta, alegadamente, uma maneira que encontrou para deixar a redação sem perder o emprego (BLACKWELL, 2007).

A ideia de realizar um trabalho jornalístico mais denso, porém, não marca exatamente um ponto de ruptura na carreira de Simon, mas sim a culminação de uma tendência crescente que ele vinha cultivando de escrever reportagens Iongas, densas e serializadas em estilo literário - reportagens estas que geraram embates com os seus editores, a quem, mesmo após a fama, Simon não mede as palavras para criticar abertamente (WILLIAMS, 2014). Segundo seu próprio ponto de vista (SIMON, 2008a), é lastimável que tenha precisado deixar o jornalismo tradicional e ir para os livros reportagem e então as ficções seriadas televisivas para realizar o trabalho que ele vê como verdadeira missão do jornalismo. Como pontua brevemente a última seção deste artigo, essa ideia de abraçar um impulso jornalístico é justamente uma das diretrizes criativas centrais que o autor traz a série, e argumentamos que ela tem grande peso tanto na conformação de um mundo ficcional singular na obra quanto da ilusão que ela cria de que se reporta 
diretamente ao nosso próprio mundo. Antes de avançar este argumento, porém, a seguir resgatamos um pouco a discussão sobre realismo, e estabelecemos a partir da obra de Ricoeur (1994) como podemos dar conta do fato de que toda ficção a um só tempo cria mundos únicos e pode ainda assim se reportar de alguma forma ao nosso.

\section{O realismo ficcional}

Os autores que se dedicaram a escrever sobre o realismo na ficção são numerosos, e algo comum nos textos sobre o tema é o caráter altamente específico das definições que por vezes são dadas ao conceito. Diversos teóricos, por exemplo, elegem um elemento formal específico para localizar ali o cerne do realismo, e Caldwell (1995) aponta como tanto a filmagem de alta qualidade em película quanto a granulação da imagem videográfica de baixa resolução já foram contraditoriamente vistas como o cerne do realismo televisivo. Outros autores, por sua vez, deslocam a contenda da abordagem formal para a abordagem temática, vendo a força do realismo no eixo dos conteúdos e não dos modos de expressão. Nestes casos, a parcialidade do olhar infelizmente ainda tende a se fazer visível, mostrando-se na eleição de um único tema ou modo de leitura temática visto como realista. Assim, o realismo estaria na escolha por retratar homens comuns ao invés de grandes heróis (FRYE, 2000) ou em uma certa "sordidez" ou "crueza" mais indefinidas na maneira de tratar quaisquer que sejam os assuntos escolhidos, um olhar que já Bazin (1991) rejeitava completamente para a questão.

Aqui, parece válido evocar as colocações de Aumont (1995), para quem tanto o realismo visto nos materiais expressivos quanto aquele enxergado nas escolhas temáticas têm em comum um caráter arbitrário e historicamente localizado, de forma que o debate precisa a um só tempo reconhecer a pertinência destes temas e formas históricos e superar a obsessão com eles. Seguindo na esteira de outro argumento de Aumont no mesmo livro, acrescentaríamos que ademais de mover o debate sobre o realismo para além dos temas e dimensões formais, é preciso ainda refutar a perspectiva que vê nele um caráter ontológico de base, 
como se as obras realistas tivessem um acesso especial à realidade (LUKÁCS, 1980) ou a imagem fotográfica/cinematográfica tivesse um vínculo indisputável com o real (BARTHES, 1984; BAZIN, 1991).

Como atesta Thompson (1988), essas perspectivas são igualmente equivocadas. No caso de um vínculo com o real, a autora repara que hoje é amplamente reconhecido que o realismo é um efeito criado por dispositivos convencionais, mencionando o caráter produtivo dos objetos de mídia, sua habilidade poética de criar uma realidade, muito mais do que de imitar a natureza. Marcadamente, essa noção casa-se com o argumento de base da teoria dos mundos ficcionais, segundo o qual a ficção vai ainda "um passo adiante" em sua força poética, criando não só uma reconstrução do nosso mundo, mas um mundo novo. Nos próprios estudos sobre documentário, aliás, este mesmo argumento é levantado, como atestam os escritos de Nichols (1991) sobre realismo.

Para o autor, do ponto de vista formal, ficção e documentário podem usar as mesmas técnicas e recursos na produção de seus realismos, que diferem sobretudo em intenção e resultado junto ao apreciador, não em configurações plásticas ou mesmo em caráter - sendo ambos ilusionistas. Segundo Nichols, a diferença é que enquanto no documentário a ideia de realismo concerne a estratégias que visam garantir veridicidade ao relato e tornar um dado argumento persuasivo em relação ao mundo em que vivemos, na ficção tal ideia diz respeito a fazer um mundo narrativo parecer real.

Notavelmente, os textos que abordam o tema dos mundos ficcionais com mais profundidade parecem concordar com essa diferença entre ficção e documentário apoiada não em marcadores estilísticos, mas no engajamento sensível com mundos de tipos distintos, por mais que ficções utilizem estratégias para tentar fazer-nos crer que se referem primariamente à realidade. Nessa perspectiva, ganham relevo os escritos que como o de Nichols buscam deslocar a questão do realismo para o domínio estético, superando o dilema ontológico-formal ao ver o núcleo da imaginação realista no eixo obra/recepção, algo que em outras oportunidades fazem inclusive os próprios Barthes e Bazin, 
baluartes da mirada ontologizante que vê as imagens fotográfica e fílmica como de antemão realistas.

No caso de Barthes (2012), por exemplo, em uma ocasião na qual escreve sobre o realismo em si e não sobre a imagem fotográfica, ele atesta que nas ficções ditas realistas o real nunca é denotado, mas entra como certa conotação/metáfora, de modo que obras realistas conotam o real, causando um "efeito de realidade" no apreciador, uma vaga e abstrata impressão de que "esta é a realidade" e de que o que vemos é "autêntico". Já conforme Bazin (1991), o realismo em arte só pode proceder de artifícios interessados em produzir a ilusão do real, criando uma tensão a um só tempo vista como inaceitável - posto que todo realismo sempre busca de algum modo restituir a realidade - e necessária - posto que ele nunca consegue alcançar este objetivo, sempre operando através de mecanismos artificiais.

Em seu ponto de vista, devido a isso devemos entender que qualquer convenção tanto rejeitada quanto abraçada pelos modos tradicionais de uso da técnica cinematográfica pode ser usada quer a serviço, quer às custas do realismo em um filme. Do mesmo modo, quaisquer avanços nos modos de expressão tidos como realistas em uma mídia para Bazin implicam por si sós em um progresso no repertório técnico disponível àqueles que trabalham nela como um todo, a despeito do realismo almejado ou rejeitado em suas intenções. Isso porque em sua visão, no contexto das obras expressivas, o problema da questão realista não é técnico. Ao contrário, não há para Bazin realismo que não seja iminentemente estético, operando necessariamente a partir de escolhas que segmentam a realidade e introduzem aquilo que dela foi segmentado em uma forma poética que já separou o segmento daquilo que nele poderia haver de real.

Nesse mesmo sentido, como repara Aumont (1995), mesmo argumentos que privilegiam certas técnicas fílmicas ou veem no cinema uma mídia mais apta que outras a capturar a realidade denunciam-nos que em termos plásticos o realismo cinematográfico nada deve à realidade. Isso por que tais argumentos são formulados sempre comparando mídias e técnicas entre si, não ao real. Isto é; se as próprias imagens do cinema - ou, entre elas, os planos abertos em 
ampla profundidade, por exemplo, seriam "mais" realistas, cabe perguntar: mais realistas em relação ao quê? O parâmetro de comparação nunca é o nosso mundo, mas sim convenções sempre arbitrárias do que se prefere no jogo interno às formas expressivas e aos esquemas intersubjetivos de percepção imagética.

Nas artes plásticas, por exemplo, Gombrich (1995) nota que tanto a perspectiva quanto a técnica do chiaroscuro criam uma sensação de tridimensionalidade em uma tela bidimensional. Uma delas, porém, privilegia volumes; a outra, profundidades, e embora possam ser associadas, qualquer comparação entre as duas em termos de qual é "mais realista" vai sempre envolver uma escolha arbitrária do que priorizar. Tal escolha, contudo, só faz sentido em relação ao que pede uma obra, não ao que pede a realidade.

Em uma linha argumentativa semelhante, Thompson atesta que qualquer uso estratégico dos elementos que compõem uma linguagem midiática para produzir a ilusão de que o mundo da obra é de antemão o nosso, ou funciona como ele, tem motivação realista, e qualquer obra que como um todo busque densamente produzir uma ilusão forte de vínculo com o real pode ser caracterizada a partir deste adjetivo. Nesse sentido, na esteira de Bazin (1991), Aumont (1995), Nichols (1991) e Barthes (2012), a autora não enxerga um cânone narrativo ou plástico organizado em torno do realismo que justifique compreendê-lo formalmente, além de rejeitar a ideia de um vínculo de base das obras realistas com a realidade. Nessa perspectiva, o realismo ficcional seria, antes de tudo, um efeito estético convocado por um constructo poético a partir do uso dos recursos de uma mídia com o objetivo de produzir junto ao apreciador uma ilusão de realidade sobre o mundo narrativo da obra. Nos termos de Gombrich (1995), o realismo é assim marcado pela sensação de vivacidade na representação, uma impressão de proximidade dela com o real, mesmo que essa proximidade seja absolutamente ilusória.

Nesse sentido, posto que o realismo é um efeito estético que pode ser convocado por uma infinidade de convenções, é preciso ter ciência de que os vários gêneros e estilos encarados como realistas através das mídias podem efetivamente ter na produção desse efeito um dos principais motivadores para 
as convenções que adotam e engendram. Não contradiz essa perspectiva, assim, falarmos em realismo poético francês ou realismo mágico. Nessa mesma direção, não há qualquer problema em especificar os elementos narrativos ou dramáticos que uma obra enfatiza na busca por estes efeitos, o que não interdita neste ponto de vista os discursos sobre realismo social, urbano, lírico, épico ou psicológico. Do mesmo modo, os mais variados tratamentos temáticos, temas, aspectos formais e usos expressivos de uma mídia podem ser contextualmente entendidos como realistas, levando-se em conta a abordagem desses elementos para produzir efeitos de real. Enfim, até mesmo as abordagens ontológicas ganham novo relevo a partir dessa definição, já que elas engendram em si mesmas convenções formais historicamente localizadas, atribuindo assim usos esquemáticos a certos recursos do meio a fim de produzir ilusões de real, observáveis em um esforço de análise.

Isso posto, porém, ainda não fica respondida a questão de como podemos aprender sobre o nosso próprio mundo por meio de ficções. Em que sentido, afinal, podemos afirmar que ficções de certa forma representam a realidade, mesmo que em um nível mais imediato criem universos de referência únicos? Um dos autores que respondem essa questão de maneira mais satisfatória é Paul Ricoeur. Desde seus trabalhos mais antigos sobre o tema da ficcionalidade, Ricoeur (1979) estabelece que embora em um nível mais imediato, denotativo, ficções representem mundos únicos, elas operam também em um segundo nível de referência, conotativo ou metafórico. Assim, mundos ficcionais poderiam ser lidos metaforicamente como o nosso, ainda que denotativamente sejam outros.

A partir dessa ideia, Ricoeur avança ao ir na teoria da metáfora, na qual há um consenso de que a referência metafórica opera justamente sobrepondo dois campos semânticos que são a rigor independentes, mas no contexto da metaforização se sobrepõem a partir de conexões que não são de todo arbitrárias, por haver certa associação aproximativa. Nesses termos, Ricoeur reconcilia a noção de mundo ficcional com a possibilidade de ficções, em um forte sentido, representarem a realidade. E nessa mirada, inclusive, o processo se mostra hermenêutico, circular, dado que uma vez lançada no mundo e consumida pelos 
apreciadores, a obra pode ter suas formas poéticas, temas, modos de construção de personagem, de metaforização e quaisquer outros aspectos lidos como parte do mundo, sendo capazes de ajudar novos autores a criar novas obras.

Nesse ponto, Ricoeur parece encontrar eco em Nichols (1991), que pensa a questão de modo afim; e em Pavel (1986), para quem a relação entre mundos ficcionais e o real é afim àquela promovida pelo texto alegórico. E aqui chegamos no que parece ser o cerne do realismo: a rigor, ele poderia ser caracterizado a partir de um esforço de tentar ocultar o fato de que a obra só pode ser lida como representação do real em um nível secundário, em uma interpretação alegórica. Assim, usando convenções e inovações estilísticas na própria configuração poética de uma obra e não referências diretas à realidade, o realismo busca esconder a própria natureza de metáfora dessa obra, o que pode se dar de múltiplas formas.

No realismo psicológico, por exemplo, a ideia pode ser fazer parecer que o abstracionismo nas convenções revela mais verdadeiramente estados internos do que poderiam mecanismos "transparentes" de narração (ANG, 1985; NICHOLS, 1991). Já no realismo do cinema clássico, inversamente, o interesse pode muitas vezes ser o de ocultar a abstração da alegoria ao invisibilizar o aparato narrativo, tentando mascarar a artificialidade da narração. Tudo isso, claro, com o intuito de fazer crer que a obra remete à realidade não por uma sobreposição de campos semânticos independentes, mas de forma direta. Em qualquer caso, a intenção é dar ao artefato alegórico (um mundo narrativo cheio de personagens, lugares e eventos inventados) a impressão de semelhança com a realidade que ele alegoriza, um senso de vivacidade na representação.

Não à toa, para autores interessados em formas sociais de realismo, questões como temas relevantes e perspectiva crítica são vistas como cerne do efeito de real: esses são elementos que mostram uma tentativa de fazer crer que a obra critica diretamente o nosso mundo, buscando dar ao artifício alegórico a aparência de referência direta ao que alegoriza. Ao analisar como uma ficção produz uma ilusão realista, nessa perspectiva, defendemos que se deve observar de que modo, mesmo criando uma esfera ontológica única (que só representa o 
real alegoricamente), a obra constrói essa esfera de forma a nos iludir quanto à sua realidade imediata.

Como as dinâmicas de produção desse mecanismo ilusório próprio do realismo são potencialmente infindas, porém, cabe ao analista empreender essa observação caso a caso, contextualmente. Por isso mesmo, observar as diretrizes autorais pode acabar se convertendo em uma chave analítica da maior importância para pesquisadores interessados nisso: ao entender como uma equipe criativa entende o vínculo entre a obra que realizam e a própria realidade, é possível observar melhor de que convenções ela lança mão para produzir uma ilusão de realidade na obra, e que inovações produz nesse mesmo sentido. Ao longo da próxima e última seção deste artigo, observamos justamente isso, tomando como exemplo a diretriz autoral de David Simon de abraçar um impulso jornalístico em The Wire.

\section{O impulso jornalístico de David Simon em The Wire}

Como pontuamos anteriormente, antes de trabalhar com seriados ficcionais, o criador de The Wire, David Simon, teve uma longa atuação como jornalista - a qual inclusive rendeu a produção de dois densos livros-reportagem, mais tarde adaptados para televisão na forma dos seriados ficcionais Homicide (NBC, 1993-1999) e The Corner (HBO, 2000). Conforme afirma o próprio Simon (et al., 2006), em parte por conta disso, uma das maiores forças condutoras das suas escolhas dramatúrgicas em The Wire era um impulso jornalístico que ele abraçava na condução do seriado. Segundo ele e diversos dos críticos que escreveram sobre a obra, é tal impulso jornalístico que orienta, por exemplo, o modo como The Wire ancora suas narrativas em debates socialmente relevantes (SIMON, 2008a, 2008b), mostra uma disposição a abraçar uma multiplicidade de vozes sociais (TSOURGIANNIS, 2016) e marca seu interesse no que Galen (2014) chamaria de tratar as realidades tematizadas no seriado de modo panorâmico ou global. Mais do que ecoar esses discursos, porém, interessa investigar como isso se traduz na série em termos concretos, e que impactos traz no modo como ela edifica um mundo único e evoca efeitos de realidade junto à apreciação. 
Para iniciar essa investigação, cabe pontuar que - por se tratar de uma série policial - obviamente muitos dos temas que The Wire aborda dizem respeito à criminalidade, aos procedimentos investigativos que orientam a polícia e ao embate entre lei e crime. E assim, muitos dos programas narrativos do seriado se centram em investigações criminais. Todavia, notavelmente, ao invés de focar essas linhas narrativas de investigação em um detetive ou par de detetives conduzindo um inquérito acerca de um criminoso ou uma organização, a ação de The Wire se desenrola, sobretudo, em nível institucional. Desse modo, partindo-se de um paradigma actancial (BALOGH, 2000; cf. GREIMAS, 1976), pode-se dizer que vistas como sujeitos, unidades ou forças-tarefas da polícia de Baltimore objetivam desmantelar certas facções criminosas. Em geral, porém, este objetivo é apenas parcialmente cumprido - líderes e traficantes menores são presos; mas as penas são curtas, os bens das facções não são confiscados e assim por diante.

Ademais, quem destina as unidades/forças-tarefas a perseguir certos criminosos na série com frequência são ou membros da alta cúpula da polícia ou os próprios detetives, muitas vezes por interesses particulares e quase nunca tendo a segurança pública em vista. Dessa forma, os destinatários que se beneficiam das investigações em curso costumam ser não os cidadãos de Baltimore, que ficarão mais protegidos, mas indivíduos implicados no jogo de ação policial membros da corporação com empenhos e rusgas pessoais, o prefeito, juízes e afins. Como na série a alta hierarquia do corpo de polícia tende a atrapalhar os inquéritos centralmente explorados tanto quanto os próprios traficantes que são alvo dessas investigações, muitas vezes além de destinarem os sujeitos a buscar certos objetivos os membros do alto escalão da polícia tendem a se juntar aos criminosos no papel de oponentes das unidades investigativas. Já contatos dos detetives (como informantes, procuradores, juízes e outros policiais) costumam assumir o papel de adjuvantes, auxiliando os núcleos de inquérito.

Como se vê, cada uma destas posições actanciais (sujeito, objeto, destinador, destinatário, adjuvante e oponente) que organizam uma linha narrativa envolve um conjunto de personagens, de modo que as tramas investigativas da série nunca são 
guiadas por fios narrativos que seguem um único detetive ou dupla, por exemplo. Ao contrário, é comum inclusive que diversos policiais de uma mesma unidade ou força-tarefa trabalhem simultaneamente em frentes distintas de inquérito, o que em si ajuda a ampliar bastante a quantidade de pontos de vista sobre cada caso policial da série. Por certo, é claro, isso não é algo totalmente novo. Afinal, são vários os seriados que seguem equipes de trabalho, e esse tipo de articulação narrativa já era comum quando da estreia de The Wire, inclusive nas séries policiais.

Ainda assim, para a época em que foi lançada, The Wire inova na tevê em duas frentes. Primeiro, ao seguir não só a equipe de detetives, mas figuras ligadas a várias das posições actanciais que estruturam seus enredos de inquérito. Conhecemos de perto membros das facções, da alta cúpula da polícia, promotores, informantes e assim por diante. Além disso, as próprias instâncias de recapitulação diegética da obra são aproveitadas para apresentar os eventos recapitulados sob a perspectiva de personagens distintas, com frequência pertencentes a núcleos e posições actanciais diversas.

Este gosto por dar relevo a vários grupos envolvidos em inquéritos investigativos é algo que Linda Williams (2014), inclusive, afirma ser não só inovador, mas inédito na televisão quando da estreia da série, e quer esse seja ou não o caso, isso sem dúvida impulsiona a multiplicidade de pontos de percepção sobre um mesmo enredo em The Wire. Além disso, ao trazer vários detetives agindo paralelamente em múltiplas frentes de inquérito, o seriado não só engendra múltiplos pontos de percepção sobre um mesmo caso, mas enredos investigativos por si sós com várias linhas paralelas de desenvolvimento distendido - fazendo com que cada detetive ou grupo de detetives siga uma pista distinta em simultâneo.

Por si só, toda essa organização narrativa (a ação orientada em torno de núcleos institucionais e não de personagens singulares, o interesse em seguir os movimentos de todos os actantes importantes para as tramas e não apenas os passos da polícia etc.) já é capaz de criar a ideia de uma grande abrangência narrativa, que facilmente nos ilude com uma ideia de abordagem total ou global da realidade alegorizada na obra, mas The Wire vai além. De fato, não contente em 
orientar a ação por núcleos e seguir todos esses núcleos, a série ainda multiplica à exaustão a quantidade de personagens que compõem cada um deles, reiterando a ideia de que traz infindas vozes sociais ao combinar esse artifício dramatúrgico com o de seguir vários agentes narrativos em uma focalização que alterna os pontos de percepção sobre o enredo7? Nesse sentido, é notável, por exemplo, o fato de que muitas personagens da série só existem para "preencher" certos núcleos institucionais produzidos na obra. Marcadamente, tais agentes narrativos têm pouca função dramática para além desta, se mostrando facilmente esquecíveis, apagados em meio às instituições que ajudam a compor - algo que ao invés de se esforçar em mitigar, o seriado faz tudo para tornar ainda mais patente.

É usual nos diálogos da série, por exemplo, a ausência de marcadores que ajudem a identificar claramente muitas de suas figuras dramáticas. Nesse sentido, é notável que os apelidos são abundantes na obra, e figuras específicas podem ser referidas pelo nome, o sobrenome, o apelido, o posto que ocupam, ou uma combinação muitas vezes variável de alguns desses termos. Um exemplo disso já no piloto é a própria menção a duas personagens diferentes pelo mesmo título de "major", sem que a obra explicite a qual dos "majores" as personagens se referem em cada instância.

Na mesma direção, também é forte no seriado a tendência a usar atores desconhecidos e até mesmo não creditar alguns deles. O produtor Robert Colesberry, por exemplo, não é creditado em sua atuação como o detetive Ray Cole, nem a atriz Jill Redding como a dona de bar Delores. E isso só se agrava dada a tendência do seriado de apresentar as suas personagens condensadamente nos primeiros episódios de cada temporada, sobretudo posto o próprio volume de figuras dramáticas engendradas em cada uma delas. Assim, a ausência de identificadores claros em muitos diálogos, a referência a alguns policiais por suas

7 Conforme os dados do IMDB, contando só papéis creditados, 99 atores participaram de ao menos dez episódios de The Wire. A título de comparação, em Game of Thrones - série constantemente mencionada pelo vasto elenco - este número foi de 84. Se estendemos a margem para o mínimo de cinco episódios, foram 168 em The Wire e 134 em Game of Thrones. Até mesmo contando todos os atores que participaram de ao menos três episódios The Wire segue na frente, com 221 deles em papéis recorrentes contra 202 de Game of Thrones. Fonte: https://www.imdb.com/. Acesso em: 05 mai. 2019. 
patentes, a homonímia e a polionímia de algumas personagens da obra, o uso de atores desconhecidos e a subcreditação de alguns deles se juntam na série à própria profusão de figuras dramáticas e introdução condensada delas para tornar difícil distinguir várias personagens. Por conta disso, com alguma frequência só o que conseguimos localizar nos diálogos sobre algumas figuras são os papéis institucionais que elas exercem. Isto é: podemos não saber a que personagem um detetive se refere em uma frase, mas em geral o contexto tende a deixar claro se o policial fala de um superior ou um alvo. As figuras dramáticas singulares, dessa forma, se tornam muitas vezes secundárias, enquanto os seus alinhamentos institucionais se tornam mais claros e contextualmente importantes.

Tudo isso vai erigindo na série um mundo de instituições maiores que os indivíduos que as articulam, com frequência esquecíveis, "apagados" ou confundíveis entre si. Em certa medida, inclusive, pode-se dizer que no seriado diversas figuras dramáticas existem somente para compor os núcleos institucionais de que fazem parte, ao invés de serem compostas neles, ajudando mais uma vez a criar um senso de mergulho no "todo" da realidade. Tais personagens ocupam apenas os papéis de "criminoso", "estivador" ou "jornalista", sendo mais do que figurantes pela sua presença em vários episódios, falas recorrentes e importância dramática mínima, mas não passando de tipos sociais. E aqui, um foco narrativo central na obra de contraposição entre instituições e indivíduos começa a mostrar claros contornos de apagamento institucional dos habitantes do mundo narrativo projetado na série - algo que é antes de tudo um enfoque temático em uma narrativa ficcional, mas cria a ilusão de ser uma crítica direta à realidade social alegorizada na obra. Nota-se, assim, que para criticar o modo como as instituições do nosso mundo oprimem alguns indivíduos, o seriado cria um outro em que isso é tão patente que ali esses indivíduos são de fato esquecíveis, meras engrenagens na máquina institucional, muitas vezes sem vidas para além disso, reduzindo-se até mesmo a tipo sociais.

Conforme argumentamos em outro lugar (ARAÚJO, 2019), vários outros elementos dramáticos se articulam nesse mesmo sentido de dar vazão ás diretrizes 
autorais de Simon e sua equipe em The Wire, incluindo aquela de abraçar um impulso jornalístico: da estrutura temporal da obra à sua ambientação, das suas texturas atmosféricas aos modos como se fecham suas temporadas, dos teasers que abrem os episódios ao modo como a série ficcionaliza eventos reais, mas cremos que os exemplos levantados aqui já são suficientes para o propósito deste artigo.

\section{Conclusão}

Ao fim deste percurso argumentativo, esperamos ter demonstrado com suficiência o quão produtivo o mapeamento de diretrizes criativas que os realizadores têm para a obra pode ser para analistas interessados nos seus aspectos formais, mormente no que concerne à composição interna dos seus mundos e seus possíveis efeitos de realidade. Afinal, dado que os efeitos realistas evocados em uma dada ficção podem se plasmar a partir de quaisquer convenções formais disponíveis aos realizadores de uma mídia, entender como uma instância autoral específica concebe esses efeitos pode fornecer pistas essenciais para quem deseja observálos em operação em um determinado contexto.

Nesse sentido, acreditamos que iniciar o processo localizando a autoria da obra em uma determinada figura ou um conjunto limitado de figuras para a partir daí mapear suas trajetórias e os impulsos criativos que demonstram ter em seus discursos sobre aquele produto parece ser um excelente caminho, permitindo que o processo de pesquisa evite dispersões e seja conduzido com foco. Mais do que tudo, explorar possibilidades de pesquisa como essas permitem superar alguns vícios nocivos ao campo, como aquele de apartar fenômenos textuais e contextuais, imaginar que qualquer consideração de autoria presume a queda em uma falácia intencional, ou ignorar os aspectos poéticos subjacentes às obras realistas e sempre analisá-las diretamente frente à realidade alegorizada.

No caso específico de The Wire, foi possível verificar que ao abraçar um assim chamado "impulso jornalístico" na condução da obra, David Simon e sua equipe puderam engendrar a partir dela diversos mecanismos que criam na série 
uma forte ilusão de real - fazendo-nos tomar, por exemplo, a abrangência dos seus núcleos pela totalidade das instituições a que eles se vinculam, sua configuração temática por um debate sobre problemas sociais concretos, e sua profusão de personagens e pontos de percepção por um mergulho total na realidade. Tudo isso nos fazendo esquecer, enquanto vemos a série, que no mundo empírico não existem pessoas que são meros tipos, as ações não se dão todas a nível institucional, e as efetivas hierarquias entre indivíduos e instituições ou agência e estrutura são alvo de constantes debates, de modo que o mundo criado na obra se singulariza e destaca do nosso justamente ao, entre outras coisas, estabelecer tais tipos sociais e hierarquias de forma clara e inequívoca para, alegoricamente, nos dizer algo sobre a realidade.

\section{Referências}

ANG, I. Watching Dallas: soap opera and the melodramatic imagination. London: Methuen, 1985.

ARAÚJO, J. E. S. "Vale tudo no jogo": a poiese de um mundo ficcional realista no seriado televisivo The Wire, 2019, Tese (Doutorado em Comunicação e Cultura Contemporâneas) - Faculdade de Comunicação, Universidade Federal da Bahia. Salvador, 2019.

AUMONT, J. A estética do filme. Campinas: Papirus, 1995.

BALOGH, A. M. O discurso ficcional na TV: sedução e sonho em doses homeopáticas. São Paulo: Edusp, 2000.

BARTHES, R. A câmara clara: notas sobre a fotografia. Rio de Janeiro, 1984. 
BAXANDALL, M. Padrões de intenção: a explicação histórica dos quadros. São Paulo: Schwarcz, 2005.

BAZIN, A. O cinema: ensaios. São Paulo: Brasiliense, 1991.

BLACKWELL, M. Fun comes down to The Wire. [s.I.]: The Daily Progress, 2007. Disponível em: https://www.dailyprogress.com/lifestyles/article_40cfad7f-854457a2-9109-3de44696c689.html. Acesso em: 02 set. 2020.

BENJAMIN, W. Origem do drama barroco alemão. São Paulo: Brasiliense, 1984.

BORDWELL, D. Historical poetics of cinema. In: PALMER, B. (ed.). The cinematic text: methods and approaches. New York: AMS, 1989.

BORDWELL, D. Figuras traçadas na luz: a encenação no cinema. Campinas: Papirus, 2008.

BOURDIEU, P. As regras da arte: gênese, estrutura e campo literário. 2a . ed. São Paulo: Companhia das Letras, 2005.

CALDWELL, J. T. Televisuality: style, crisis, and authority in American television. New Brunswick: Rutgers University Press, 1995.

DOLEŽEL, L. Heterocosmica: fiction and possible worlds. Baltimore: The Johns Hopkins University Press, 1998.

ECO, U. Seis passeios pelos bosques da ficção. São Paulo: Schwarcz, 2006. . Lector in fabula: a cooperação interpretativa nos textos narrativos. 2a. ed. São Paulo: Perspectiva, 2008. 
FRYE, N. Anatomy of criticism: four essays. Princeton: Princeton University Press, 2000.

GOMBRICH, E. Arte e ilusão: um estudo sobre a psicologia da representação pictórica. 2a. ed. São Paulo: Martins Fontes, 1995.

GOMES, W. Estratégias de produção de encanto: o alcance contemporâneo da poética de Aristóteles. Textos de cultura e comunicação, Salvador, v. 35, n. 1, 1996.

GoOdMAN, N. Modos de fazer mundos. Porto: Asa, 1995.

GREIMAS, A. J. Semântica estrutural. 2ª ed. São Paulo: Cultrix, 1976.

HERMAN, D. Narrative ways of worldmaking. In: HEINEN, S.; SOMMER, R. (eds.). Narratology in the age of cross-disciplinary narrative research. Berlin: De Gruyter, 2009.

LUKÁCS, G. Realismo crítico hoje. Brasília: Coordenada, 1969.

MITTELL, J. Complex TV: the Poetics of contemporary television storytelling. New York: New York University Press, 2015.

NICHOLS, B. Representing reality. Bloomington: Indiana University Press, 1991.

PAVEL, T. Fictional worlds. Cambridge: Harvard University Press, 1986.

RICOEUR, P. Tempo e narrativa. Vol. 1. Campinas: Papirus, 1994. . "The function of fiction in shaping reality". Man and world, New York, v. 12, n. 2, 1979. 
RONEN, R. Possible worlds in literary theory. Cambridge: Cambridge University Press, 1994.

RYAN, M. L. Possible worlds, artificial intelligence, and narrative theory. Indiana: University Bloomington \& Indiana Press, 1991.

SIMON, D. A final thank you to The Wire fans, from show creator David Simon. [s.I.]: HBO, 2008a. Disponível em: https://www.hbo.com/the-wire/a-final-thankyou-to-the-wire-fans. Acesso em: 02 set. 2020.

. Introduction. In: ALVAREZ, R. (ed.). The Wire: truth be told. New York: Pocket Boos, 2004.

. The Wire's final season and the story everyone missed. [s.I.]: The Huffington Post, 2008b. Disponível em: https://www.huffingtonpost.com/davidsimon/the-wires-final-season-an_b_91926.html. Acesso em: 02 set. 2020.

SIMON, D. et al. Exclusive David Simon Q\&A. [s.l.]: The Wire on HBO: play or get played on David Simon's Baltimore, 2006. Disponível em: http://www.borderlineproductions.com/TheWireHBO/exclusive-1.html. Acesso em: 02 set. 2020.

SIMON, D. et al. I'm David Simon, creator of HBO's The Wire, The Corner, Show Me A Hero, now working on The Deuce. I'm also a 2010 MacArthur Fellow. Go ahead and AMA. [s.I.]: Ask Me Anything, 2016. Disponível em: https://www.reddit.com/ r/IAmA/comments/51lz1y/im_david_simon_creator_of_hbos_the_wire_the/. Acesso em: 02 set. 2020.

THOMPSON, K. Breaking the glass armor: neoformalist film analysis. Princeton: Princeton University Press, 1988. 
TOUS-ROVIROSA, A. El concepto de autor en las series norteamericanas de calidad. In: SERAFIM, J. F. (org.). Autor e autoria no cinema e na televisão. Salvador: Editora da UFBA, 2009.

TSOURGIANNIS, Y. Documentaries, realism and fiction: how real is real in the work of David Simon. [s.I.]: Film Parlato, 2016. Disponível em:http://filmparlato.com/ index.php/numeri/6/item/143-serial-filmmakers-david-simon. Acesso em: 02 set. 2020.

WILLIAMS, L. On the Wire. Durham (North Carolina): Duke University Press, 2014.

WILSON, G. "The bigger the lie, the more they believe": cinematic realism and the anxiety of representation in David Simon's The Wire. South Central Review, Baltimore, v. 31, n. 2, 2014.

Submetido em: 2 set. 20 | aprovado em: 14 out. 20 